\title{
PROPRIEDADES MECÂNICAS DE UMA JUNTA DE AÇO C-Mn SOLDADA PELO PROCESSO HÍBRIDO LASER- GMAW*
}

\author{
Fernando Antônio Corrêa \\ Jeferson Frederico Monteiro Costa ${ }^{2}$ \\ Jorge Carlos Ferreira Jorge ${ }^{3}$ \\ Luís Felipe Guimarães de Souza ${ }^{3}$
}

\section{Resumo}

O processo de soldagem híbrido LASER- GMAW, comumente designado por HLAW (Hybrid Laser Arc Welding), foi concebido há bastante tempo, mas só recentemente começou a ser aplicado industrialmente. Nesse trabalho foi feita uma avaliação do seu desempenho na soldagem de chapas de aço C-Mn com 10mm de espessura. As juntas produzidas foram avaliadas por meio de ensaios de impacto Charpy-V e mapeamento de microdureza Vickers, além da caracterização microestrutural. Também foram realizadas, medições dos níveis das tensões residuais introduzidas na junta soldada pelo processo híbrido, comparativamente com o processo GMAW robotizado. Os resultados da avaliação de desempenho do processo híbrido mostraram uma maior produtividade em relação ao GMAW robotizado. As propriedades mecânicas da junta soldada se mostraram compatíveis com os requisitos do material de base.

Palavras-chave: Soldagem Híbrida; MIG-Laser; Aço C-Mn

\section{MECHANICAL PROPERTIES OF WELDED JOINT OBTAINED BY HYBRID LASER-GMAW PROCESS}

\section{Abstract}

Hybrid Laser-GMAW process, generally known as HLAW (Hybrid Laser Arc Welding), was developed many years ago, but only recently started to be used in industrial applications. In this work, it has been done an evaluation of its process performance when welding a $10 \mathrm{~mm}$ thick plate of a C-Mn Steel, as well as, the determination of mechanical properties and metallurgical structure of the welded joint, using impact and hardness tests and microstructural characterization. Residual stress was also measured in the plate welded with hybrid process, comparatively to a welded joint performed with robotized GMAW process. The results of performance evaluation of hybrid process showed that it has higher productivity when compared to robotized GMAW. The mechanical properties of the hybrid welded joint were in accordance with base metal requirements.

Keywords: Hybrid Welding; HLAW; C-Mn Steel.

Eng. Mecânico, FIRJAN, IST de Solda e Mestrando. CEFET/RJ,PPEMM, RJ, Brasil.

Eng. Metalúrgico, M.Sc, Doutorando, CEFET/RJ, PPEMM, RJ, Brasil.

Eng. Metalúrgico, D.Sc., Professor Titular do CEFET/RJ, PPEMM, Rio de Janeiro, RJ, Brasil. 


\section{INTRODUÇÃO}

A tecnologia LASER foi desenvolvida em meados do século passado (1960), e teve como uma de suas primeiras aplicações o corte térmico. Como decorrência natural, logo em seguida ela foi introduzida na soldagem [1]. A alta concentração de calor proporcionada pelo feixe LASER colimado, se mostrava como uma ferramenta muito promissora, particularmente para a aplicação na soldagem. Entretanto, o passar dos anos mostrou que a necessidade de uma preparação de junta com pouca margem de variação para a obtenção de boa reprodutibilidade na operação, aliado ao alto custo das fontes LASER de alta potência, tornaram o processo limitado à aplicações onde o volume de produção justificava esse alto investimento. Dispositivos de soldagem sofisticados e processos de corte de alta qualidade são requisitos básicos para garantir o grau de preparação de junta necessário à obtenção de soldas LASER consistentes e de alta performance [2-3].

Esta limitação do processo de soldagem LASER apresentada no parágrafo anterior ensejou o desenvolvimento de tecnologias híbridas de soldagem, de modo a aproveitar as grandes vantagens do processo de soldagem LASER e mitigar suas limitações. Inúmeros processos foram desenvolvidos (TIG-LASER, MIG-LASER, Plasma-LASER, GMAW Duplo Arame-LASER, etc.), todos buscando aumentar a capacidade do processo em resistir a pequenas falhas na preparação da junta [4-6]. Em paralelo, o rápido desenvolvimento da tecnologia LASER, produzindo equipamentos de menor custo, compactos e de maior potência, justificou esse investimento na flexibilização da soldagem LASER, pois essa tecnologia passou a ser mais viável, no que se refere ao investimento inicial. Estudar os fenômenos que decorrem da interação entre o feixe LASER e o arco elétrico nos processos híbridos (HLAW) passou a ter maior relevância, em função do incremento de seu potencial de aplicação [7-8].

Os processos híbridos tem um grau de complexidade mais elevado que os processos convencionais, uma vez que além das complexidades inerentes a cada processo individualmente, existe também a necessidade de considerar os fenômenos relacionados com as interações entre os dois processos [6,9]. No caso específico da soldagem híbrida LASER-GMAW os efeitos sinérgicos entre os processos já foram observados experimentalmente e são bastante significativos [9]. O maior desafio nesse particular é o grande número de variáveis envolvidas, incluindo o tipo de laser utilizado na célula híbrida, além das características geométricas do cabeçote híbrido.

A solda híbrida produzida pelo processo LASER-GMAW possui duas regiões características: a primeira é uma região de penetração profunda e bem estreita, onde a influência do processo LASER predomina. A segunda região, no topo do cordão, onde predomina o processo GMAW [4]. A Figura 1 ilustra essa característica marcante dos cordões de solda do processo híbrido LASER-GMAW.

O trabalho de Acuña [5] faz referência a um experimento realizado pelo EWI (Edison Welding Institute), no qual é realizada a soldagem híbrida LASER-GMAW de uma junta de aço estrutural, utilizando um arame-eletrodo de aço inoxidável. Nesse experimento, ficou bem evidente, que a diluição na região do arco elétrico é bem menor, enquanto que na região do LASER próximo à raiz, a diluição é praticamente a da solda autógena. A Figura 2 apresenta a macrografia da solda referente a esse experimento. 


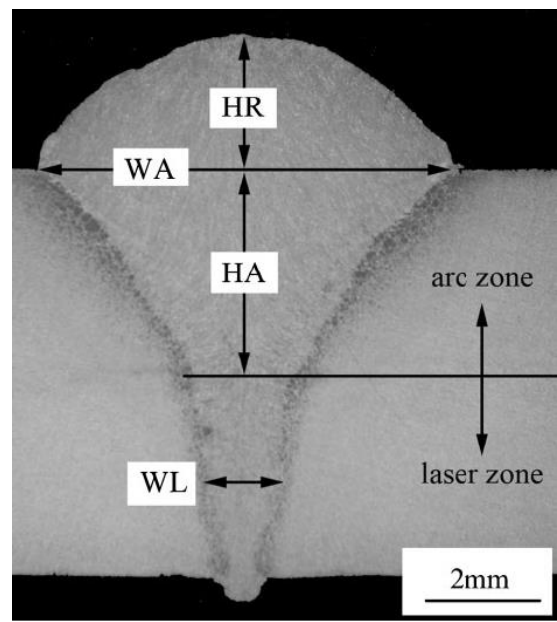

Figura 1. Macrografia ilustrando o aspecto do cordão de solda, indicando a região de predominância do arco (arc zone) e a região de predominância do LASER (laser zone). HR, HA, WL e WA são parâmetros dimensionais do cordão [4].

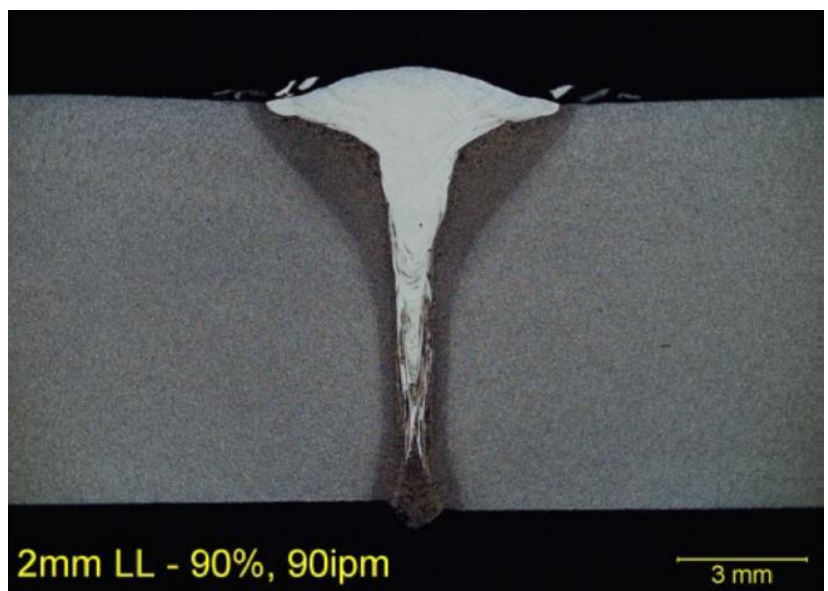

Figura 2. Macrografia de uma junta de aço estrutural soldada com o processo híbrido usando um consumível de aço inoxidável [5].

O presente trabalho é um dos pioneiros no Brasil a avaliar essa tecnologia, que já começa a ser utilizada industrialmente nos EUA, na Europa e na Ásia $[4,8]$. O objetivo do trabalho foi avaliar as propriedades mecânicas de uma junta soldada com o processo híbrido LASER-GMAW, no passe de raiz e enchimento, numa junta de aço C-Mn composta por chapas de $10 \mathrm{~mm}$ de espessura. O passe de acabamento foi realizado com o processo GMAW convencional, visando permitir a avaliação do efeito deste passe sobre a estrutura e propriedades do cordão de solda híbrido subjacente.

\section{MATERIAIS E MÉTODOS}

\subsection{Materiais}

Como material de base, foi utilizada uma chapa de aço carbono, sendo que cada componente da junta tinha as dimensões de $170 \mathrm{~mm} \times 55 \mathrm{~mm} \times 10 \mathrm{~mm}$. Como material de adição, foi utilizado o arame-eletrodo AWS A5.18 ER70S-6 [10] de $1 \mathrm{~mm}$ de diâmetro. A Tabela 1 mostra a composição química dos materiais.

O gás de proteção utilizado tanto na soldagem GMAW robotizada como na soldagem híbrida LASER-GMAW foi a mistura binária composta por $20 \%$ de $\mathrm{CO}_{2} \mathrm{e}$ balanço em Argônio. 
Tabela 1. Composição química dos metais de base e de adição utilizados na soldagem híbrida e GMAW robotizada.

\begin{tabular}{l|c|c|c|c|c|c}
\hline Material & $\% \mathrm{C}$ & $\% \mathrm{Mn}$ & $\% \mathrm{Si}$ & $\% \mathrm{P}$ & $\% \mathrm{~S}$ & $\% \mathrm{Fe}$ \\
\hline Metal Base & 0,184 & 0,430 & 0,0276 & 0,0137 & 0,0130 & Balanço \\
\hline Metal de Adição & 0,08 & 1,45 & 0,95 & 0,011 & 0,013 & Balanço \\
\hline
\end{tabular}

\subsection{Métodos}

A soldagem híbrida LASER-GMAW foi realizada numa célula composta por uma fonte LASER de disco Yb:YAG com potência máxima de16kW, comprimento de onda de $1030 \mathrm{~nm}$ e qualidade 2-8mm.rad; uma fonte de soldagem GMAW com capacidade máxima de $400 \mathrm{~A}$; e um cabeçote híbrido (distância feixe LASER-arco constante e igual a zero). A otimização dos parâmetros foi realizada a partir de parâmetros desenvolvidos para cada processo individualmente. No caso da soldagem LASER, ajustou-se inicialmente os parâmetros que promoveram a solda com iminência de penetração total. Na soldagem GMAW, buscou-se parâmetros que promovessem um cordão de solda com bom acabamento e boa velocidade de soldagem. Os ajustes posteriores para a soldagem híbrida foram feitos mantendo-se a regulagem do LASER e ajustando o arco elétrico e a abertura da junta, visando obter um cordão híbrido de penetração total homogênea e preenchimento da junta. O critério adotado para a otimização do processo foi o aspecto visual da raiz e da face do cordão, e análise macrográfica das juntas aprovadas visualmente.

As Tabelas 2 e 3 mostram os parâmetros de soldagem que foram utilizados na soldagem da chapa de teste após o processo de otimização.

Tabela 2. Parâmetros de Soldagem para o Processo LASER-GMAW.

\begin{tabular}{l|c}
\hline Potência LASER & $7.265 \mathrm{~W}$ \\
\hline Corrente de Soldagem & $194 \mathrm{~A}$ \\
\hline Velocidade do Arame & $11,6 \mathrm{~m} / \mathrm{min}$ \\
\hline Tensão do Arco & $26,8 \mathrm{~V}$ \\
\hline Inclinação do cabeçote & $15^{\circ}$ \\
\hline Velocidade de Soldagem & $1740 \mathrm{~mm} / \mathrm{min}$ \\
\hline Distância Laser - arco elétrico & $0 \mathrm{~mm}$ \\
\hline
\end{tabular}

A distância LASER-Arco Elétrico nesse cabeçote é fixa.

Tabela 3. Parâmetros de Soldagem para o Processo GMAW Robotizado e para o passe de acabamento na chapa soldada com o processo híbrido.

\begin{tabular}{l|c|c}
\hline \multicolumn{1}{c|}{ Parâmetros } & Robotizado & Acabamento \\
\hline Corrente de Soldagem & $133,9 \mathrm{~A}$ & $147,7 \mathrm{~A}$ \\
\hline Velocidade do Arame & $5,44 \mathrm{~m} / \mathrm{min}$ & $5,4 \mathrm{~m} / \mathrm{min}$ \\
\hline Tensão do Arco & $19,1 \mathrm{~V}$ & $18,8 \mathrm{~V}$ \\
\hline Inclinação da tocha & $15^{\circ}$ & $15^{\circ}$ \\
\hline Velocidade de Soldagem & $180 \mathrm{~mm} / \mathrm{min}$ & $240 \mathrm{~mm} / \mathrm{min}$ \\
\hline Distância Bico de Contato Peça & $15 \mathrm{~mm}$ & $13 \mathrm{~mm}$ \\
\hline
\end{tabular}

A chapa de teste soldada com o processo híbrido Laser-GMAW foi dividida em duas partes iguais, sendo a primeira parte para realização dos ensaios mecânicos (impacto Charpy- $V$ e mapeamento de microdureza), ensaios metalográficos (macrografia e micrografia) e análise química do metal de solda. A segunda parte da chapa de teste soldada foi encaminhada para a execução do passe de acabamento com o processo GMAW. Após o passe de acabamento, foram retirados corpos de prova para os 
ensaios, de forma análoga a da outra metade da chapa.

$O$ ensaio de impacto Charpy- $V$ foi realizado na temperatura ambiente $\left(23^{\circ} \mathrm{C}\right) \mathrm{em}$ corpos de prova reduzidos de dimensões $5,0 \mathrm{~mm} \times 10 \mathrm{~mm} \times 55 \mathrm{~mm}$, de acordo com a norma ASTM E 23, tipo A [11], usinados a partir da raiz da solda com o entalhe posicionado no centro do metal de solda. Foram produzidos 3 corpos de prova para as chapas soldadas (com e sem cordão de acabamento) e 5 corpos de prova para 0 metal base.

O ensaio de microdureza Vickers foi efetuado com carga de $0,2 \mathrm{kgf} / 15 \mathrm{~s}$. Realizouse um mapeamento na região da solda (metal de base, ZTA e metal de solda) de 1405 pontos, varrendo toda a espessura da chapa, utilizando um durômetro automático Shimadzu HMV-G. O espaçamento entre as identações foi de $0,3 \mathrm{~mm}$.

A análise metalográfica foi realizada utilizando o procedimento padrão de preparação das amostras (lixamento e polimento até a pasta de diamante de granulometria de $1 \mu \mathrm{m}$ ). $\mathrm{O}$ ataque químico foi feito com reagente Nital $2 \%$, sendo a macrografia feita com a lupa estereoscópica e a micrografia no microscópio óptico (MO).

Foi realizada análise química do metal de base (chapa) e do metal de solda por espectrometria de emissão óptica nos pontos de medição indicados na Figura 3.

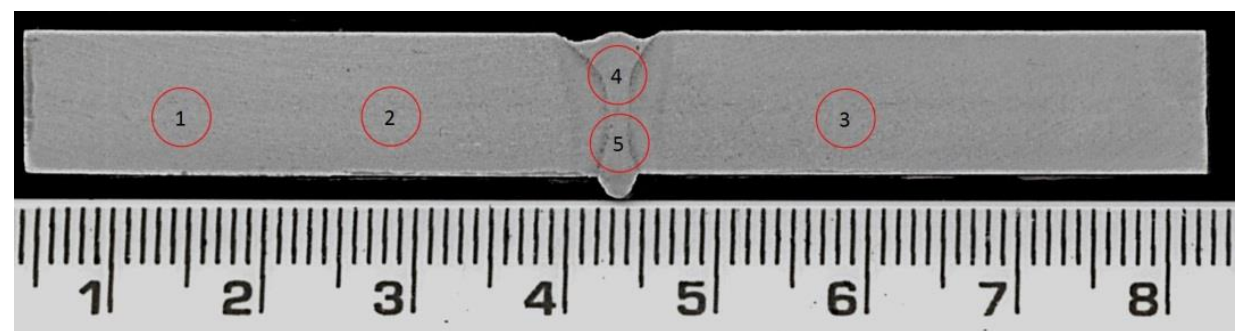

Figura 3. Macrografia da junta soldada com processo LASER-GMAW indicando os pontos onde foram efetuados a análise química.

\section{RESULTADOS E DISCUSSÃO}

A Figura 4 mostra as macrografias da junta soldada, onde se observa que o ciclo térmico do cordão de acabamento provocou uma modificação estrutural em parte do cordão de solda híbrido e em parte de sua ZTA. Essas modificações podem ser observadas nas micrografias mostradas na Figura 5.

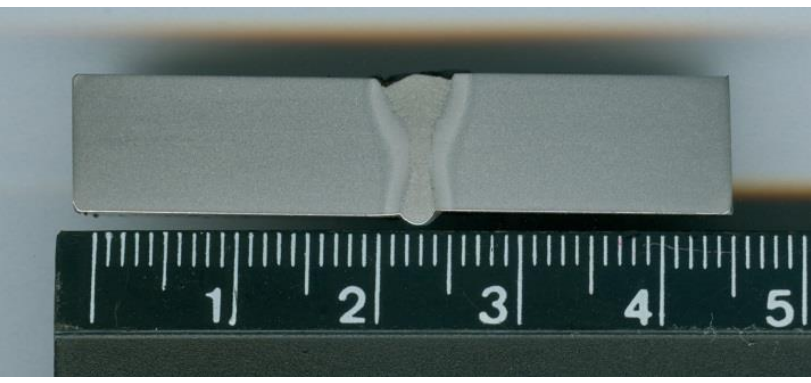

(A)

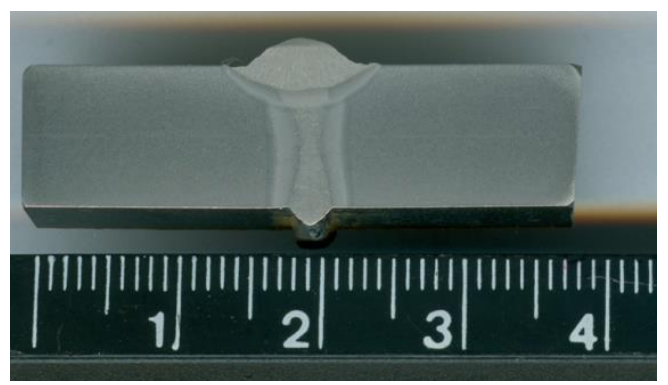

(B)

Figura 4. Macrografias das soldas híbridas. (A) sem cordão de acabamento (B) com cordão de acabamento

Na Figura 5 fica evidente que a estrutura do cordão de solda híbrido com cordão de acabamento GMAW é bem mais refinada que a do cordão híbrido sem cordão de acabamento, na posição $A$, a $0,5 \mathrm{~mm}$ da superfície da junta. Nessa posição, o metal de solda é essencialmente o cordão de acabamento depositado com o processo 
GMAW. Dessa forma, a menor quantidade de metal de solda fundido e as condições de resfriamento, relativamente alto, por se tratar de um passe de acabamento, promoveram a formação de uma estrutura bem mais refinada.

Já na posição $B$, a 2,5mm da face da solda, a qual se encontra $1 \mathrm{~mm}$ abaixo do cordão de solda de acabamento, se observa o beneficiamento do ciclo térmico desse cordão sobre a estrutura colunar original. Finalmente, na posição $C$, relativa à $5 \mathrm{~mm}$ da superfície do cordão, nota-se que ambos os metais de solda apresentam uma estrutura grosseira, já sem indícios de transformações promovidas pelo cordão de acabamento GMAW. Esse mesmo padrão se repete para todas as demais análises até a raiz da solda.

Posição Solda sem cordão de acabamento Solda com cordão de acabamento

A
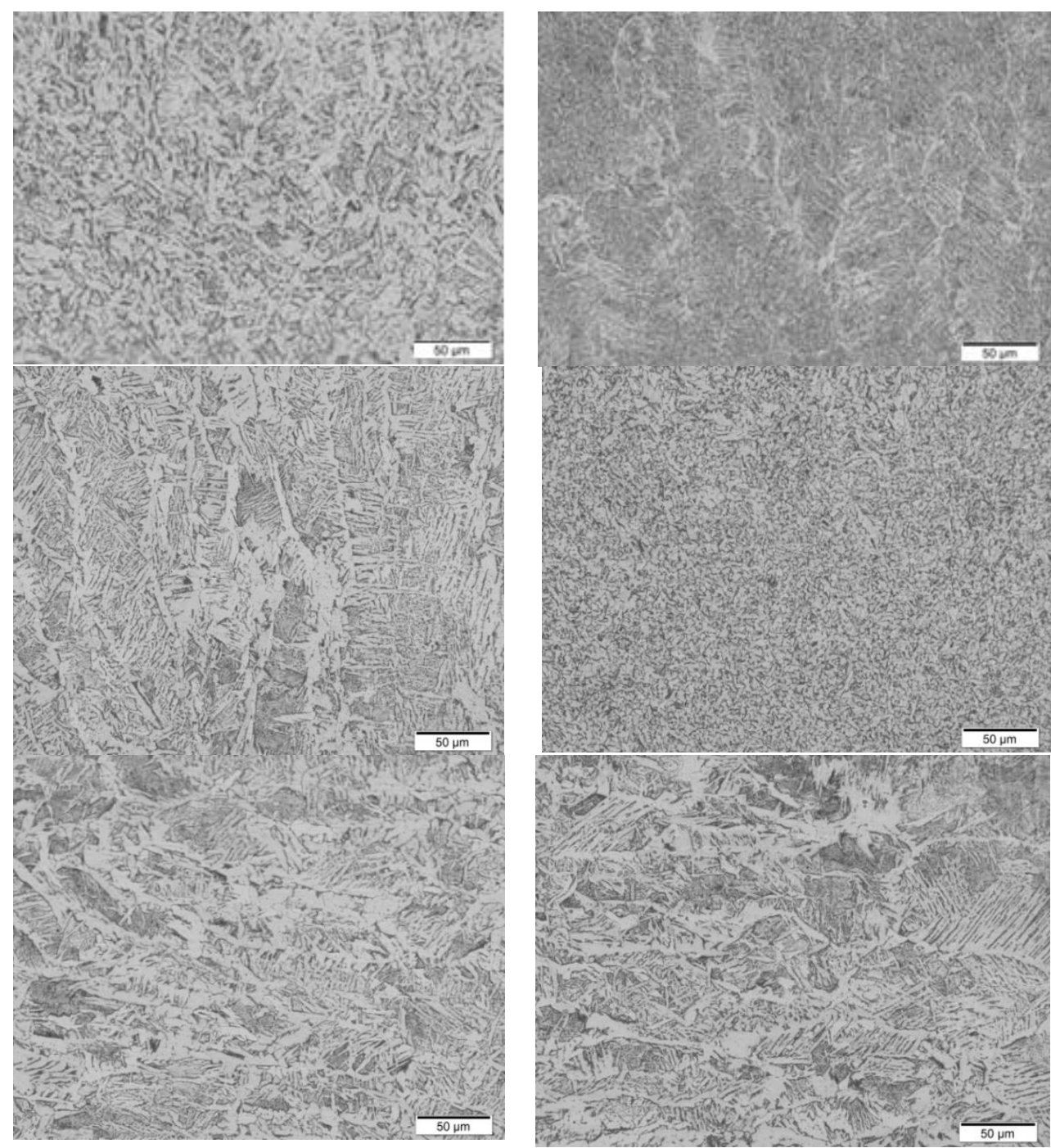

Figura 5. Microestruturas do centro do metal de solda em diferentes posições em relação à superfície da junta: (A) a 0,5mm; (B) a 2,5mm (C) a 5,0mm. Ataque: Nital $2 \%$.

A Figura 6 apresenta os mapas de microdureza $\left(\mathrm{HV}_{0.2}\right)$ para cada uma das condições, onde foram determinados 1.405 pontos em cada junta. 


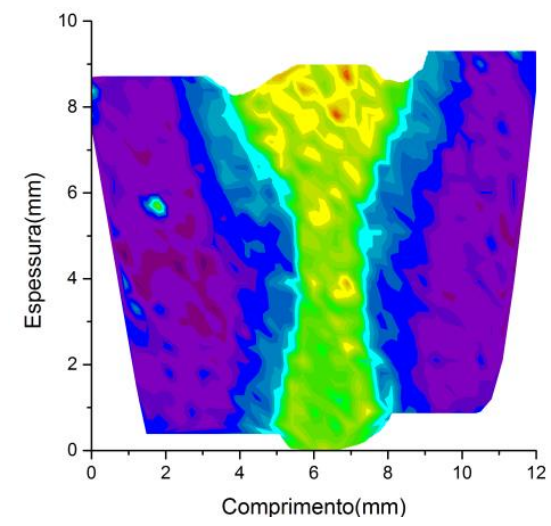

Solda sem cordão de acabamento

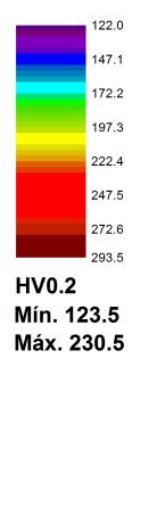

Figura 6. Mapa de microdureza das juntas soldadas.

A análise dos mapas permite visualizar o efeito da diluição progressiva em direção a raiz, conforme relatado pelo EWI [5]. Fica claro que o metal de adição de maior resistência promove valores de dureza mais elevados na região de predominância do arco elétrico, onde a diluição é mais baixa. Na raiz da solda (região de predominância do LASER com alta diluição) a dureza é menor, mas ainda sim maior que a do material de base, por conta da estrutura grosseira de grãos colunares.

A análise química no cordão de solda sem cordão de acabamento, nos pontos 4 e 5 da Figura 3, apresentada na Tabela 4, confirma a afirmativa do parágrafo anterior com relação à diluição. $\mathrm{O}$ teor de silício no ponto 4 é quase quatro vezes maior que 0 teor desse elemento no metal de base. Naturalmente que esse efeito é promovido pela participação do metal de adição, que possui um teor de silício trinta vezes maior que o do metal de base. Já no ponto 5 , que está mais próximo da raiz, a participação do metal de adição é menor, devido a maior diluição, e nesse, o incremento no teor de silício é pouco maior que duas vezes o do metal de base.

Tabela 4. Composição química do metal de solda da junta sem acabamento.

\begin{tabular}{c|c|c|c|c|c|c}
\hline $\begin{array}{c}\text { (\%Peso) } \\
\text { Posição }\end{array}$ & $\% \mathrm{C}$ & $\% \mathrm{Mn}$ & $\% \mathrm{Si}$ & $\% \mathrm{P}$ & $\% \mathrm{~S}$ & $\% \mathrm{Fe}$ \\
\hline 4 & 0,146 & 0,546 & 0,102 & 0,0128 & 0,0141 & Balanço \\
\hline 5 & 0,157 & 0,447 & 0,0686 & 0,0149 & 0,0136 & Balanço \\
\hline Metal Base & 0,184 & 0,430 & 0,0276 & 0,0137 & 0,0130 & Balanço \\
Desvio Padrão & 0,012 & 0,009 & 0,0022 & 0,0007 & 0,0006 & \\
\hline Metal de Adição & 0,08 & 1,45 & 0,95 & 0,011 & 0,013 & Balanço \\
\hline
\end{tabular}

Efeito similar, mas um pouco menos intenso, é observado no teor de manganês, pois nesse caso a diferença de teor entre metal de adição e metal de base é bem menor, da ordem de três vezes. No ponto $4 \mathrm{o}$ incremento em relação ao teor de manganês no metal de base é da ordem de $23 \%$, enquanto que no ponto 5 esse valor cai para algo próximo a $4 \%$.

No caso do teor de carbono, o efeito é inverso, pois o teor desse elemento no metal de base é mais elevado que no metal de adição, de um fator aproximado de duas vezes. No ponto 4 o teor de carbono está aproximadamente $20 \%$ mais baixo que o do metal de base, enquanto que no ponto 5 é aproximadamente $15 \%$ menor.

Portanto, as diferenças de composição química nos pontos 4 e 5 indicadas na tabela 4 estão compatíveis com valores de diluição mais elevados no ponto $5 \mathrm{e}$ menores no ponto 4 . 
Outro aspecto que corrobora os experimentos de outros autores [5,12] é que a região crítica em termos de propriedades mecânicas situa-se na interseção da região de predominância do arco com a de predominância do LASER. Nesse aspecto, o mapa da amostra com cordão de acabamento indica que a execução deste passe parece ter intensificado esse efeito, entre as cotas $2,5 \mathrm{~mm}$ e $5 \mathrm{~mm}$, da face do cordão.

A Tabela 5 mostra os resultados dos ensaios de impacto Charpy- $V$, onde se pode observar que não houve diferença significativa entre os corpos de prova com e sem o cordão de acabamento, como já era possível prever pelo resultado da análise micrográfica dessa região abaixo da cota de $5 \mathrm{~mm}$ da face do cordão. Cumpre registrar a ocorrência de uma maior dispersão de resultados para os corpos de prova da amostra sem acabamento. A dispersão de resultados no ensaio de impacto Charpy-V é relativamente comum, em particular quando a região a ser ensaiada não apresenta uma microestrutura homogênea [13]. Na média, os resultados do metal de solda foram superiores aos apresentados pelo metal de base, caracterizando que, no caso do aço aqui utilizado, a execução da soldagem híbrida com um único passe não promoveu efeitos nocivos na tenacidade ao impacto do metal de solda, região da junta soldada que pode ser considerada crítica, devido ao elevado grau de diluição que aproxima a composição química do metal base, associada com a presença de grãos colunares.

Tabela 5. Resultados dos ensaios de impacto Charpy- $V$ realizados na temperatura ambiente. Valores médios de 3 corpos de prova para cada condição.

\begin{tabular}{c|c|c}
\hline Condição & Energia absorvida (joules) & Desvio Padrão \\
\hline Sem acabamento & 64,0 & 14,9 \\
\hline Com acabamento & 57,2 & 7,0 \\
\hline Metal base* & 37,5 & 1,0 \\
\hline \multicolumn{2}{c}{${ }^{\star}$ O resultado é média de 5 corpos de prova }
\end{tabular}

Alguns autores [7,14-17] relatam dificuldades semelhantes as que foram observadas nesse trabalho com relação à estabilização da raiz da solda, seja em função de variações na configuração da junta, ou mesmo, devido ao ajuste de parâmetros de soldagem. Allen et al.[7] inclusive estabeleceu limites para aberturas nas juntas em função da espessura da chapa. Gook et al.[17], por outro lado, optou por controlar os excessos de penetração localizados reduzindo a tensão do arco, aumentando a velocidade de soldagem e incrementando a potência do LASER. Nesse caso, o objetivo era obter homogeneidade na composição química do metal de solda, pois tratava-se da soldagem de aço de alta resistência, que demandava a participação do metal de adição na composição do metal de solda para o desenvolvimento das propriedades mecânicas compatíveis com os requisitos do metal de base.

Zhang et al.[18] soldando aço C-Mn encontrou resultados semelhantes, em termos de níveis de dureza e microestrutura no metal de solda. Os resultados na região do LASER do passe de raiz (nesse trabalho a soldagem híbrida foi multipasses) foram os mais baixos devido a estrutura colunar grosseira do metal de solda. Entretanto, os resultados nessa região foram superiores ao do metal de base, assim como no presente trabalho, indicando que a solda teve uma boa performance.

\section{CONCLUSÃO}

Esse trabalho inicial com a tecnologia híbrida de soldagem LASER-GMAW de chapas de aço C-Mn com 10mm de espessura, com e sem passe de acabamento com o processo GMAW, permite as seguintes conclusões: 
(a) A soldagem híbrida LASER-GMAW é um processo de relativa complexidade devido ao grande número de variáveis que podem influenciar significativamente no resultado final. Entretanto, utilizando-se uma metodologia consistente para a seleção de parâmetros de soldagem, é possível produzir juntas sem descontinuidades significativas e com propriedades mecânicas compatíveis com os requisitos do material de base.

(b) As juntas produzidas com o processo híbrido LASER-GMAW apresentaram uma diluição progressiva (menor na face e maior na raiz do cordão), em conformidade com o relato de outros pesquisadores.

(c) O cordão de acabamento executado sobre a solda híbrida LASER-GMAW produziu mudanças significativas nas propriedades mecânicas e na microestrutura da metade superior da junta soldada.

\section{Agradecimentos}

Os autores agradecem à CAPES e ao CNPq pelo apoio financeiro, ao CEFET/RJ pelo suporte e infraestrutura; ao Sistema FIRJAN, através do IST Solda, pelo suporte e infraestrutura e ao Laboratório MTC, pelo importante auxílio no corte e usinagem de corpos de prova.

\section{REFERÊNCIAS}

$1 \quad$ Bertolotti M. The History of the Laser. London, UK: IOP Publishing; 2005.

2 Quintino L. et al. Welding with High Power Fiber Lasers- A preliminary Study. Materials \& Design. 2007; 28(4): 1231-1237.

3 Leong $\mathrm{KH}$ et al. Threshold Laser Beam Irradiation Melting and Welding. J. of Laser Applications. 1997; 9(5): 227-231.

4 Gao M. Zeng X. Hu Q. Yan J. Welding Microstructure and Shape of Laser Arc Hybrid Welding. Science and Technology of Welding and Joining. 2008; 13(2):103113.

5 Acuña AFF. Hybrid Laser Welding in API X65 and X70 Steels. Thesis (Master Degree) The Ohio State University, USA; 2016.

6 Steen WM. Arc Augmented Laser Processing of Materials. Journal of Applied Physics. 1980;51:5636-5641.

7 Allen CM. Gerritsen CHJ. Zhang Y. Mawella J. Hybrid Laser-MAG Welding Procedures and Weld Properties in $4 \mathrm{~mm}, 6 \mathrm{~mm}$ and $8 \mathrm{~mm}$ Thickness C-Mn Steels. IIW Commission IV / XII, Intermediate Meeting. Vigo, Spain; 2007.

8 Moore PJ., Howse DS. Wallach ER. Microstructures and Properties of Laser/Arc Hybrid Welds and Autogenous Laser Welds in Pipeline Steels. Science and Technology of Welding and Joining. 2004; 3: 314-322.

9 Hu B. den Ouden G. Synergetic Effects of Hybrid Laser/Arc Welding. Science and Technology of Welding and Joining. 2013;10: 427-431.

10 AWS A5.18 -Specification for Carbon Steel Electrodes and Rods for Shielded Arc Welding. 2007.

11 ASTM E23 -16b Standard Test Methods for Notched Bar Impact Testing of Metallic Materials. 2016b

12 Karlsson L. Svensson L. Hurtig K. Influence of Dilution on Properties of High Strength Steel Weld Metals. Byuletyn Instytutu Spawalnictwa. 2014; 5: 62-70.

13 Dieter GE. Metalurgia Mecânica, 2 ed, Rio de Janeiro, Brasil, Guanabara Dois. 1981.

14 Metzbower EA. et al. Thermal Analysis and Microhardness Mapping in Hybrid Laser Welds in a Structural Steel. Materials Science Forum. 2003; 426-432: 41474152. 
15 Ribic B. Palmer TA. DebRoy T. Problems and Issues in Laser-Arc Hybrid Welding, International Materials Reviews. 2009; 54: 223-244.

16 Nolting A. Munro C. Cao XJ. Wajara P. Mechanical Properties of HSLA-65 Hybrid Laser Arc Welds. Canadian Metallurgical Quarterly. 2012; 51: 336-345I

17 Gook S. Gumenyuk A. Rethmeier M. Hybrid Laser Arc Welding of X80 and X120 Steel Grade, Science and Technology of Welding and Joining. 2014;19(1):15-24.

18 Zhang C. Li G. Gao M. Zeng XY. Microstructure and Mechanical Properties of Narrow Gap Laser-Arc Hybrid Welded 40mm Thick Mild Steel. Materials. 2017;10(106):1-10. 